DOI: $10.12737 /$ article_5967e947072e89.35181372

УДК 581.9 (470.32)

ОХРАНА БИОРАЗНООБРАЗИЯ АРИДНЫХ ЭКОСИСТЕМ ЦЕНТРАЛЬНОГО ЧЕРНОЗЕМЬЯ РОССИИ доктор географических наук, профессор А. Я. Григорьевская ${ }^{1}$

А. С. Субботин ${ }^{1}$

О. В. Якименко ${ }^{1}$

кандидат географических наук Д. Р. Владимиров ${ }^{1}$

А. А. Рудницких ${ }^{1}$

1 - ФГБОУ ВО «Воронежский государственный университет», г. Воронеж, Российская Федерация

Приводится краткая характеристика биоразнообразия псаммофитных, кальцефитных и галофитных экосистем с указанием типичных и редких для Центрального Черноземья представителей флоры, в числе которых Caragana scythica - новый вид для данного региона. Нахождение узкого эндемика неогенового возраста бассейна Северского Донца Hedysarum ucrainicum. Среди редких растений эндемиками Донецкого кряжа и юга Приволжской возвышенности являются Hyssopus cretaceus, Polygala cretacea, Silene cretacea, в Европейской части России - Cephalaria uralensis, Chamaecytisus zingeri Галофитная флора насчитывает около 230 видов растений, среди которых имеются виды-индикаторы степени засоления почвы. В псаммофитных сообществах растуг эндемичные для юга Европейской России и бассейна Дона растения. Псаммофитные аридные экосистемы приурочены к левобережью реки Дон и его притокам - Воронежу, Потудани, Хопру, Битюгу и др. Флора их насчитывает до 300 видов сосудистых растений. Кальцефитные аридные экосистемы занимают меловые отложения на юге Среднерусской возвышенности. Флора их насчитывает около 550 видов. Данные аридные экосистемы можно назвать источниками информации для познания генезиса как самих кальцефитных экосистем, так и растительного покрова юга Русской равнины. Аридные экосистемы как природные комплексы отражают целесообразное, неповторимое, уникальное сочетание организмов и ландшафтов биома Земли. Большую угрозу аридным экосистемам представляет процесс адвентивизации. Охрана биоразнообразия аридных экосистем обосновывается ценностью реликтовой биоты, необходимой для познания научных, теоретических, практических вопросов генезиса, динамики биоразнообразия в целях организации рационального природопользования и стабилизации природного компонента биосферы.

Ключевые слова: Охрана биоразнообразия, аридные экосистемы, Центральное Черноземье, новый вид, эндемики, местонахождения.

\title{
PROTECTION OF BIODIVERSITY OF ARID ECOSYSTEMS OF CENTRAL CHERNOZEM ZONE OF RUSSIA
}

DSc in Geography, Professor A. I. Grigorievskaya ${ }^{1}$

\author{
A. S. Subbotin ${ }^{1}$ \\ O. V. Yakimenko ${ }^{1}$ \\ $\mathrm{PhD}$ in Geography D. R. Vladimirov ${ }^{1}$
}

A. A. Rudnickikh ${ }^{1}$

1 - Federal State Budget Education Institution of Higher Education «Voronezh State University», Voronezh, Russian Federation

\begin{abstract}
Brief overview of biodiversity of psammophyte, calciphyte and halophytic ecosystems with indication of typical and rare for Central Chernozem region of flora is given, including Caragana scythica, new species for this region. Finding a narrow endemic Neogene-age basin of the Seversky Donets - Hedysarum ucrainicum. Among the rare plants, endemics to the Donets ridge and the south of Volga upland are Hyssopus cretaceus, Polygala cretacea, Silene cretacea, in the European part of Russia Cephalaria uralensis, Chamaecytisus zingeri. Halophytic flora includes about 230 species of plants, among which there are indicator-species of soil salinity. In psammophyte communities plants, endemic to the South of European Russia and the Don basin,
\end{abstract}




\section{Природопользование}

grow. Psammophyte arid ecosystems are confined to the left Bank of the Don River and its tributaries: Voronezh, Potudan, Khoper, Bityug, etc. Their flora includes 300 species of vascular plants. Calciphyte arid ecosystems occupy the Cretaceous sediments in the South of Central Russian upland. Their flora includes about 550 species. These arid ecosystems can be called sources of information for understanding the Genesis of the calciphyte ecosystems and vegetation of the South Russian plain. Arid ecosystems as natural systems reflect the appropriate unique combination of organisms and landscapes of the biomes of the Earth. A major threat for arid ecosystems is the process of adventinization. Protection of biodiversity of arid ecosystems is justified by the value of relict biota, essential for understanding scientific, theoretical, practical issues of genesis and dynamics of biodiversity in order to organize rational nature management and stabilization of the natural component of the biosphere.

Keywords: protection of biodiversity, arid ecosystems, the Central Chernozem, new species, endemics, locations.

Биоразнообразие аридных экосистем формируется в жёстких условиях среды, испытывая дефицит влаги, действие высокой температуры воздуха и других факторов. Жёсткие параметры жизни биоты корректируются диапазоном толерантности. Так, у некоторых растений имеется длинный корень, опушение войлочного типа и т. д. Эти морфологические признаки помогают им добывать воду с глубины и экономить её при испарении.

Биота аридных экосистем имеет узкий диапазон толерантности и поэтому приурочена к биотопам, отвечающим её экологическим требованиям. В других условиях экотопов она не способна существовать. Значит, узкая экологическая специализация биоты аридных экосистем является важным обоснованием её охраны.

Дадим краткую характеристику биоразнообразия псаммофитных, кальцефитных и галофитных аридных экосистем. Они относятся к разным вариантам степей.

1. Псаммофитные аридные экосистемы приурочены к левобережью реки Дон и его притокам Воронежу, Потудани, Хопру, Битюгу и др. Флора их насчитывает до 300 видов сосудистых растений.

Учёными установлено, что пески отложились водными потоками рек и являются речными, однако водные потоки отступающего ледника также приняли небольшое участие. Для их рельефа характерны песчаные бугры - «кучугуры», или одиночные дюны - «буруны» как результат действия ветра [3]. Заслуживают изучения урочища «Дюнные всхолмления» площадью 197,6 га и «Видногое» площадью 101,4 га, расположенные в окрестностях сёл Березняги и Дедовка Петропавловского района с координатами 49 $52^{\prime} 8.27 "$ с. ш., $40^{\circ} 56^{\prime} 7.0^{\prime \prime}$ в. д. Существовавший в прошлом сосновый лес был сведён, что привело к движению песка. В
1930 г. эти места посетил энтомолог Н.Н. Кунаков и отмечал подвижные дюны.

После Великой Отечественной войны и в последующие годы проводились посадки Pinus sylvestris и $P$. pallasiana, что привело частично к закреплению песка. Изучение энтомофауны выполнено К.В. Скуфьиным. Он обнаружил виды насекомых, родина которых находится в черноморско-казахстанских степях и полупустынях. Из юго-восточных видов встречаются чернотелка бродячая, чернотелка суженная, чернотелка укороченная. Также отмечены жук-скакун, жукнарывник сирийский, оса-аммофила, много диких пчёл, шмелей [6].

В псаммофитных сообществах растуг эндемичные для юга Европейской России и бассейна Дона растения, такие как: Asperula graveolens, Centaurea pineticola, C. dubjanskyi, C. sophiae, Anchusa popovii, Herniaria euxina. Отмечаются растения-псаммофиты: Senecio borysthenicus, Jurinea ewersmannii, Chamaecytisus borysthenicus, Betula borysthenica, кустистая форма Quercus robur.

В настоящее время уже сформировался псаммофитный аридный комплекс с редкими элементами биоты.

Урочища «Дюнные всхолмления» и «Видногое» являются памятниками природы областного значения (Постановление Правительства Воронежской области от 25.12.2013 № 1161; Постановление Администрации Воронежской области от 28.05.1998 № 500).

2. Кальцефитные аридные экосистемы занимают меловые отложения на юге Среднерусской возвышенности. Мощные залежи таких отложений имеются на правобережье реки Дон и его притоках. Флора их насчитывает около 550 видов.

В кальцефитных аридных экосистемах доминируют растения жизненных форм: кустарнички, полу- 


\section{Природопользование}

кустарнички, низкорослые кустарники. Они имеют одревесневшие корни, стебли и другие приспособительные признаки, чтобы выживать в жёстких условиях среды. Для этих экосистем ещё характерны «сниженные альпы», иссопники, меловые тимьянники, полынники с реликтовой флорой разных географических зон.

Данные аридные экосистемы можно назвать источниками информации для познания генезиса как самих кальцефитных экосистем, так и растительного покрова юга Русской равнины. Богатыми сведениями о реликтовых растениях располагают урочища в окрестностях села Волоконовка Кантемировского района, правобережье р. Толучеевка Калачеевского района, окрестности села Дерезовка Верхнемамонского района и ряд других.

Нахождение узкого эндемика неогенового возраста бассейна Северского Донца - Hedysarum ucrainicum на правобережье рек Белой и Айдара (Белгородская область РФ, Украина), а также Hedysarum cretaсеит по р. Толучеевка в Калачеевском и Петропавловском районах дают предположение о формировании меловой растительности в Воронежской области в третичное время [1].

Для более чёткого представления о богатстве и ценности кальцефитных аридных экосистем приведём характеристику формации Lepidium.

Формация клоповниковая (Lepidium) имеет координаты 4950'2.5" с. ш., 39¹9'12.6" в. д. и находится в Кантемировском районе, окрестности с. Волоконовка. Меловые обнажения правобережья р. Белой являются единственным местонахождением в ЦЧР полукустарничка Lepidium meyeri и Scabiosa isetensis [4]. Богатое видовое разнообразие (528 видов) с 25 растениями Красной книги РФ и 65 - Красной книги Воронежской области характерно для данного урочища, и оно, по предположению С. В. Голицына, является одним из центров зарождения кальцефитной флоры на Среднерусской возвышенности [4]. Список растений Красной книги РФ (2011) следующий: 1 - Jurinea cretacea, 2 - Artemisia hololeuca, 3 - A. salsoloides, 4 - Erucastrum cretaceum, 5 - Lepidium meyeri, 6 - Matthiola fragrans, 7 - Silene cretacea, 8 - Cephalaria uralensis, 9 Genista tanaitica, 10 - Hedysarum ucrainicum, $11-H$. grandiflorum, 12 - Bellevalia sarmatica, 13 - Iris aphylla, 14 - Iris pumila, 15 - Hyssopus cretaceus, 16 - Thymus cimicinus, 17 - Fritillaria ruthenica, 18 - Bulbocodium versicolor, 19 - Paeonia tenuifolia, 20 - Stipa dasyphylla, 21 - S. pennata, 22 - S. pulcherrima, 23 - S. zalesskii, $24-$ Pulsatilla pratensis, 25 - Scrophularia cretacea [5].

Среди редких растений эндемиками Донецкого кряжа и юга Приволжской возвышенности являются Hyssopus cretaceus, Polygala cretacea, Silene cretacea; Европейской части России - Cephalaria uralensis, Chamaecytisus zingeri; Среднего Дона - Festuca cretacea, Koeleria talievii, Artemisia hololeuca, Diplotaxis cretacea, Erysimum cretaceum, Scrophularia cretacea; Северского Донца - Genista tanaitica, Hedysarum ucrainicum; юга Европейской части - Centaurea carbonata, Alyssum gymnopodium, Thymus calcareus, Linum ucrainicum, Asperula exasperata, Astragalus pallescens, Iris pineticola, Allium podolicum, Jurinea creticola; юга Среднерусской возвышенности - Androsace koso-poljanskii; юговостока Европы и Западного Казахстана - Lepidium meyeri, Linaria cretacea.

При отсутствии единого мнения о возрасте эндемиков из-за недостатка достоверных, в основном палеоботанических сведений, реликтами миоценплиоцена, видимо, можно считать Artemisia hololeuca, Silene cretacea; плейстоцена - Festuca cretacea, Asperula tephrocarpa, Diplotaxis cretacea, Hedysarum ucrainicum $[7,8]$.

Богатая информация о биоте аридных экосистем не является исчерпывающей. Найдена Caragana scythica (эндемик) - новый вид для Центрального Черноземья России. Она растёт в Богучарском районе, в окрестностях с. Белая Горка, на меловых останцах с координатами 49॰47'37.9" с. ш., 4057'42.7" в. д. (VORG. 17.06.2016) [4]. Отмечается в Крыму, Причерноморье, Молдавии, на Нижнем Дону [9].

3. Галофитные аридные экосистемы характерны для засоленных почв, которые отмечаются спородически в регионе изучения. Растения имеют ряд приспособлений к засолению почвы, т. е. свой диапазон галотолерантности. Галофитная флора насчитывает около 230 видов растений, среди которых имеются виды-индикаторы степени засоления почвы. На сильно засоленных почвах (солончаках) растут Salicornia prostrata, Suaeda prostrata, S. acuminata, Petrosimonia triandra и др. На средне- и слабозасоленных почвах растут Plantago cornuti, Lepidium latifolium, Scorzonera parviflora, Carex deluta и т. д. На почвах от сильнозасо- 


\section{Природопользование}

ленных до средне- и слабозасоленных растуг Juncus gerardii, Spergularia salina и др. [2]. Редкие виды, такие как Ferula caspica, F. tatarica, Serratula cardunculus, Galatella divaricata, нуждаются в охране.

Флорогенез галофильной флоры связан с Древним Средиземноморьем, Европой и Азией $[10,11,12]$.

Богата и разнообразна фауна аридных экосистем. Млекопитающие, птицы являются хорошими агентами зоохории. Они разносят семена плодовых деревьев и способствуют облесению экосистем. Землерои изменяют микрорельеф и усиливают пятнистость растительности. Богатый и разнообразный мир насекомых-опылителей. Шмели, бабочки, дикие одиночные пчелы, цветочные мухи и др. выполняют неоценимо важную работу. Представители трофической цепи - микроорганизмы ещё хорошо не изучены.

Аридные экосистемы как природные комплексы отражают целесообразное, неповторимое, уникальное сочетание организмов и ландшафтов биома Земли.

Большую угрозу аридным экосистемам представляет процесс адвентивизации. Внедрение Cyclachaena xanthiifolia, Ambrosia trifida, A. artemisiifolia, Hieracleum sosnowskyi и других видов ведет к сокращению биоразнообразия, изменению структуры сообщества, появлению аллергенных болезней у человека и т. д.

Охрана биоразнообразия аридных экосистем обосновывается ценностью реликтовой биоты, необходимой для познания научных, теоретических, практических вопросов генезиса, динамики биоразнообразия в целях организации рационального природопользования и стабилизации природного компонента биосферы.

Для сохранения биоразнообразия аридных природных экосистем требуется знать причины его сокращения. Причины многофакторные и связаны с: 1 природными процессами, например, изменением климата; 2 - степенью трансформации экосистем; 3 - радиационной обстановкой в регионе; 4 - биологогенетическими особенностями биоты.

Положительное решение данных проблем видится в: 1 - рациональной фитомелиорации по новым технологиям антропогенно-преобразованных участков; 2 - определении тенденции и выявлении причин изменения климата; 3 - научном подходе изучения и разработки новых технологий по сохранению биоразнообразия аридных экосистем.

\section{Библиографический список}

1. Абрамова, Т. И. К вопросу о размещении меловой растительности в Ростовской области [Текст] / Т. И. Абрамова, С. В. Голицын, А. Я. Григорьевская // Вопросы ландшафтной географии. - Воронеж, 1969. - С. $42-47$.

2. Агафонов, В. А. Степные, кальцефильные, псаммофильные и галофильные эколого-флористические комплексы бассейна Среднего Дона: их происхождение и охрана [Текст] / В. А. Агафонов. - Воронеж, 2006. - 250 с.

3. Бережной, А. В. Песчаные буруны [Текст] / А. В. Бережной // Воронежские дали. - Изд. 2-е. - Воронеж, 1981. - С. 22-24.

4. Гербарий сосудистых растений (VORG): кадастр. Т. 1 [Текст] / А. Я. Григорьевская, В. И. Федотов, Д. Ю. Зелепукин, О. В. Якименко ; под ред. А. Я. Григорьевской. - Воронеж : Научная книга, 2016. -358 с.

5. Красная книга Воронежской области: в 2 т. Т. 1. Растения. Лишайники. Грибы [Текст] : учеб. - Воронеж : МОДЭК, 2011. - $472 \mathrm{c}$.

6. Скуфьин, К. В. В песчаном царстве [Текст] / К. В. Скуфьин // Воронежские дали. - Изд. 2-е. - Воронеж, 1981. C. 234-235.

7. Талиев, В. И. Ещё о флоре каменистых склонов [Текст] / В. И. Талиев // Известия Имп. СПб. бот. сада. 1902. - Т. 2. - Вып. 7. - С. 203-217.

8. Талиев, В. И. К вопросу о реликтовой растительности ледникового периода [Текст] / В. И. Талиев // Труды Общества испытателей природы при Императорском Харьковском университете. - 1897. - Т. 31. - С. 127-241.

9. Цвелев, Н. Н. Карагана - Caragana Lam. [Текст] / Н. Н. Цвелев // Флора европейской части СССР. - Л. : Наука, 1987. - T. 6. - C. 39-45.

10. The return of the steppe:Large-scale restoration of degraded land in southern Russia during the post-Soviet era [Text] / N. Hoelzel [et al.] // Journal for Nature Conservation (Jena), 2002. - №. 10. - P. 75-85. 


\section{Природопользование}

11. Knapp, P. A. Spatio-temporal patterns of large grassland fires in the Intermountain West [Text] / P. A. Knapp // USA. Global Ecology and Biogeography, 1998. - № 7. - P. 259-272.

12. Kullman, L. Post Little Ice Age tree line rise and climate warming in the Swedish Scandes: a landscape ecological perspective [Text] / L. Kullman, L. Oberg // Journal of Ecology, 2009. - Vol. 97 (3). - P. 415-429.

\section{References}

1. Abramova T.I., Golitsyn S.V., Grigoryevskaya A.Ya. K voprosu o razmeshchenii melovoy rastitel'nosti v Rostovskoy oblasti [To a question of placement of cretaceous vegetation in the Rostov region] Voprosy landshaftnoy geografii [Questions of landscape geography]. Voronezh, 1969, pp 42-47. (In Russian).

2. Agafonov V. A. Stepnye, kal'tsefil'nye, psammofil'nye i galofil'nye ekologo-floristicheskie kompleksy basseyna Srednego Dona: ikh proiskhozhdenie i okhrana [Steppe, calcicole, psammofilny and galofilny ekologo-floristic complexes of the basin of Central Don: their origin and protection]. Voronezh, 2006, 250 pp. (In Russian).

3. Berezhnaya A. V. Peschanye buruny [Sandy breakers of]. Voronezhskie dali [Voronezh distances]. Prod. the 2nd. Voronezh, 1981, pp. 22-24. (In Russian).

4. Grigorevskaya A.Ja., Fedotov V.I., Zelepukin D.Ju., Jakimenko O.V. Gerbarij sosudistyh rastenij (VORG): kadastr [Herbarium vascular plants (VORG): inventory] Voronezh, 2016, Vol 1, 358 p. (In Russian).

5. Krasnaya kniga Voronezhskoy oblasti: v 2 t. Rasteniya. Lishayniki. Griby [Red List of the Voronezh region: in 2 t. Plants. Lichens. Mushrooms]. Voronezh, 2011, vol. 1, 472 pp. (In Russian).

6. Skufyin K. V. [In a sandy kingdom of], Voronezhskie dali [Voronezh distances]. Prod. the 2nd. Voronezh, 1981, pp. 234-235. (In Russian).

7. Taliev V.I. Eshche o flore kamenistykh sklonov [About flora of stony slopes], Izv. Imp. Spb. bot. sada. 1902. Vol. 2, Issue 7, pp. 203-217. (In Russian).

8. Taliev V.I. $K$ voprosu o reliktovoy rastitel'nosti lednikovogo perioda [To a question of relic vegetation of Ice Age]. Trudy Obshchestva ispytateley prirody pri Imperatorskom Khar'kovskom universitete [Works of Society of testers of the nature at Imperial Kharkiv university]. 1897, Vol. 31, pp.127-24. (In Russian).

9. Tsvelev N. N. Karagana - Caragana Lam. [of Karagan - Caragana Lam.], Flora evropeyskoy chasti SSSR [Flora of the European part of the USSR], Leningrad, 1987, Vol. 6, pp. 39-45. (In Russian).

10. Hoelzel N., Haub C., Ingelfinger M.P., Otte A., Pilipenko V.N. Vozvrashchenie stepi: krupnomasshtabnoe vosstanovlenie ukhudshennoy zemli v yuzhnoy Rossii v techenie postsovetskoy ery [The return of the steppe: Large-scale restoration of degraded land in southern Russia during the post-Soviet era]. Zhurnala dlya Okhrany okruzhayushchey sredy (Jena) [Journal for Nature Conservation (Jena)], 2002, no. 10, pp. 75-85.

11. Knapp P.A. Prostranstvenno-vremennye obraztsy bol'shogo polya strelyayut v Mezhgoru na zapad [Spatio-temporal patterns of large grassland fires in the Intermountain West]. SShA, Global'nuyu Ekologiyu i Biogeografiyu [USA, Global Ecology and Biogeography], 1998, no. 7, pp. 259-272.

12. Kullman, L. Oberg L. Ob"yavite o Nebol'shom povyshenii ryada derev'ev Lednikovogo perioda i klimate, nagrevayushchemsya v shvedskom Scandes [Post Little Ice Age tree line rise and climate warming in the Swedish Scandes] Peyzazh ekologicheskaya perspektiva, Zhurnal Ekologii [A landscape ecological perspective, Journal of Ecology], 2009, Vol. 97 (3), pp. 415-429.

\section{Сведения об авторах}

Григорьевская Анна Яковлевна - профессор кафедры геоэкологии и мониторинга окружающей среды факультета географии, геоэкологии и туризма ФГБОУ ВО «Воронежский государственный университет», доктор географических наук, профессор, г. Воронеж, Российская Федерация; e-mail: grigaya@mail.ru.

Субботин Артем Сергеевич - магистрант кафедры геоэкологии и мониторинга окружающей среды факультета географии, геоэкологии и туризма ФГБОУ ВО «Воронежский государственный университет», г. Воронеж, Российская Федерация, e-mail: art8266@yandex.ru. 


\section{Природопользование}

Якименко Ольга Владимировна - магистрант кафедры геоэкологии и мониторинга окружающей среды факультета географии, геоэкологии и туризма ФГБОУ ВО «Воронежский государственный университет», г. Воронеж, Российская Федерация; e-mail: zemfirka@inbox.ru.

Владимиров Дмитрий Романович - старший преподаватель кафедры рекреационной географии, страноведения и туризма факультета географии, геоэкологии и туризма ФГБОУ ВО «Воронежский государственный университет», кандидат географических наук, г. Воронеж, Российская Федерация; e-mail: kvint_88@mail.ru.

Руднииких Алина Амерановна - магистрант кафедры геоэкологии и мониторинга окружающей среды факультета географии, геоэкологии и туризма ФГБОУ ВО «Воронежский государственный университет», г. Воронеж, Российская Федерация; e-mail: djesika-89@mail.ru.

\section{Information about authors}

Grigorevskaya Anna Yakovlevna - Professor of Department of Geography, Geoecology and Tourism, Federal State Budget Education Institution of Higher Education «Voronezh state University», DSc in geography, Professor, Voronezh, Russian Federation; e-mail: grigaya@mail.ru.

Subbotin Artem Sergeyevich - master, department of geoecology and environmental monitoring, department of geography, geoecology and tourism, Federal State Budget Education Institution of Higher Education «Voronezh state University», Voronezh, Russian Federation; e-mail: art8266@yandex.ru.

Yakimenko Olga Vladimirovna - master, department of geoecology and environmental monitoring, department of geography, geoecology and tourism, Federal State Budget Education Institution of Higher Education «Voronezh state University», Voronezh, Russian Federation; e-mail: zemfirka@inbox.ru.

Vladimirov Dmitry Romanovich - Senior lecturer of the department of recreational geography, regional geography and tourism, faculty of geography, geoecology and tourism, Federal State Budget Education Institution of Higher Education «Voronezh state University», PhD in geography, Voronezh, Russian Federation; e-mail: kvint_88@mail.ru.

Rudnitskikh Alina Ameranovna - master, department of geoecology and environmental monitoring, department of geography, geoecology and tourism, Federal State Budget Education Institution of Higher Education «Voronezh state University», Voronezh, Russian Federation; e-mail: djesika-89@mail.ru.

DOI: $10.12737 /$ article_5967e9653fc089.77407015

УДК: 581.5/9: 631.9/470.63

ЭКОЛОГО-ФЛОРИСТИЧЕСКАЯ СИТУАЦИЯ ОБЪЕКТОВ ЛЕСОМЕЛИОРАЦИИ В АГРОЛАНДШАФТАХ СТАВРОПОЛЬСКОГО КРАЯ

кандидат биологических наук Л. В. Дудченко ${ }^{1}$ кандидат биологических наук Н. Г. Лапенко ${ }^{1}$ кандидат биологических наук В. А. Дружинин ${ }^{1}$

1 - ФГБНУ «Ставропольский научно-исследовательский институг сельского хозяйства», Ставропольский край, г. Михайловск, Российская Федерация

В статье рассматриваются материалы исследования объектов лесомелиорации - полезащитных лесополос Ставрополья. Дана оценка состояния древесной растительности и травянистого покрова лесополос, предложен способ улучшения фитосанитарной ситуации в них. Условия проведения исследований - зона неустойчивого увлажнения, включающая районы - Грачевский, Изобильненский, Кочубеевский, Шпаковский. Фактический материал получен на основе геоботанического обследования полезащитных лесополос и согласно требованиям методик, общепринятых в фитоценологии. Результаты исследования показали, что древесная растительность лесополос нуждается в комплексе лесомелиоративных мероприятий, направленных на повышение устойчивости, природоохранных, санитарногигиенических и оздоровительных свойств лесополос. Постоянным негативным фактором полезащитных лесополос 